\begin{tabular}{|l|l|}
\hline \multicolumn{1}{|c|}{$\begin{array}{c}\text { Mechanics Research Communications. } \\
\text { Year }\end{array}$} & $\begin{array}{c}\text { Publication Office: } \\
\text { Elsevier UK }\end{array}$ \\
\hline $\begin{array}{l}\text { Editor-in-Chief:A. Rosato New Jersey Institute of Technology, Newark, New Jersey, } \\
\text { USAAnthony.Rosato@njitedu }\end{array}$ & \\
\hline
\end{tabular}

\title{
Thermal Behavior of Elastic Columns with Second-mode Imperfections
}

\author{
Jianguo $\mathrm{CAI}^{*}$, Yangqing $\mathrm{LIU}^{1}$, Jian $\mathrm{FENG}^{2}$, Yixiang $\mathrm{XU}^{3}$
}

${ }^{1}$ Key Laboratory of C \& PC Structures of Ministry of Education, Southeast University, Nanjing 210096, China

${ }^{2}$ National Prestress Engineering Research Centre, Southeast University, Nanjing 210096, China

${ }^{3}$ Department of Civil Engineering, Strathclyde University, Glasgow, United Kingdom

*caijg_ren@hotmail.com; j.cai@seu.edu.cn

Tel.:+86-25-8379-5006; fax: +86-25-8379-3150

Accepted: .

\begin{abstract}
Pin-ended columns having an initial imperfection in a second buckling mode and subjected to thermal loading have been studied in this paper. Based on a nonlinear relationship between strains and displacements, the buckling equilibrium equations are given with the energy method. Then the formulae for the axial compression and transversal displacement are presented. The relationship between the anti-symmetric imperfection and the axial compression has been studied along with the effect of elevated temperature on the initial imperfection. The response of the column in fire to the modified slenderness ratio is investigated. The proposed method has the potential to provide more detailed information for column designs and thus be deployed in future research to minimize the need for expensive laboratory testing.
\end{abstract}

\section{[Graphical Abstract]}

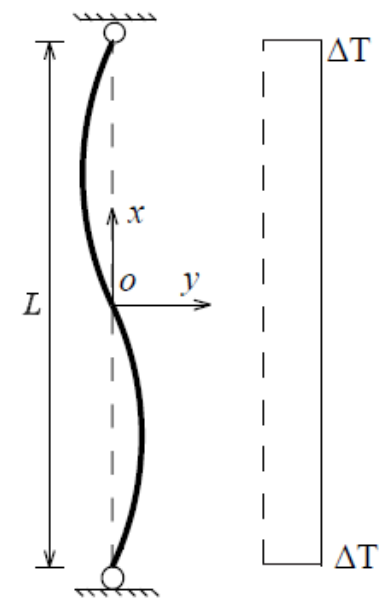

(C) 2015 The Authors.Published by Elsevier Ltd.

Keywords: Columns, Buckling, Imperfections, Steel, Thermal loading. 


\begin{tabular}{|c|c|}
\hline $\begin{array}{l}\text { Mechanics Research Communications. } \\
\text { Year }\end{array}$ & $\begin{array}{l}\text { Publication Office: } \\
\text { Elsevier UK }\end{array}$ \\
\hline 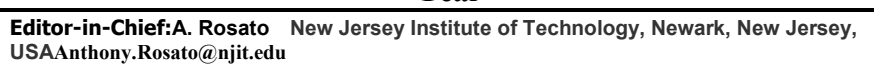 & \\
\hline
\end{tabular}

\section{Introduction}

The stability of axially-loaded perfect columns is a classical problem. The classical Euler equation is often used to predict the elastic buckling loads (Timoshenko and Gere [1], Simitses [2]). However, the mechanical behavior of steel structures subjected to fire conditions has received increasing attention in recent years. General background about the behavior of steel structures at elevated temperatures can be found in many literatures, such as Buchanan [3] and Wang [4].

The fire resistance of steel columns, which are the main load-carrying members, has been studied analytically, numerically and experimentally by many researchers. A finite difference approach was proposed by Culver [5] to investigate the behavior of wide-flanged steel columns under elevated temperature. Based on the experimental results, Poh and Bennetts [6] proposed a numerical model for the thermal behavior of steel columns. Toh et al. [7] established a simple analytical method to examine the compressive resistance of steel columns at specified temperature levels. A number of steel columns subjected to fire conditions were loaded to their limit states by Yang et al. [8] to check the mechanical behavior of steel columns in fire. Cai and Feng [9] studied the in-plane elastic buckling of a steel column with under thermal loading. Then Cai et al. [10] also investigated the effects of load-dependent supports on the thermal behaviour of steel columns. Correia et al. [11] proposed a simplified calculation method for fire design of steel columns with restrained thermal elongation. Alam et al. [12] studied the lateral load resistance of non-insulated steel columns under fire exposure with the finite element method.

It should be noted that the mechanical behavior of steel columns with imperfections is different from perfect columns. Often the shape of the imperfection is assumed to be similar to the first buckling mode (symmetric shape) of the perfect columns [13-15].However, the imperfection shape of the columns may have the shape of the second buckling mode (anti-symmetric shape). The post-buckling of pinned and cantilevered columns with asymmetric imperfections was studied by Plaut et al. [16]. Rotationally restrained columns having an initial imperfection in an asymmetric mode have been studied by Cai et al [17]. The investigation of the effects of anti-symmetric imperfections on the thermal behavior of elastic columns has been quite rarely reported in the literatures.
An accurate and reliable analytical formula to predict the behavior of steel columns subject to elevated temperatures is very important, because the cost of the full-scale experiments under fire conditions is high. The objective of this paper is to establish a theoretical model for the mechanical behavior of steel columns under thermal loadings. Moreover, the influence of second-mode imperfections on the thermal behavior of steel columns is also studied. Based on the nonlinear strain-displacement relationship, the principle of virtual work is used to establish the nonlinear equilibrium equations. The formulae for the axial force and displacement are also given.

\section{Basic theories of columns}

A pin-ended column with a second-mode imperfection (anti-symmetric shape) is shown in Fig. 1. The axis system is selected as being centroidal with the origin at mid-height of the column. The relationship between element strains and nodal displacements will be given firstly. An imperfect column with a small initial curvature is considered in this paper. All the assumptions for normal slender columns are satisfied except that the column now has an initial shape.

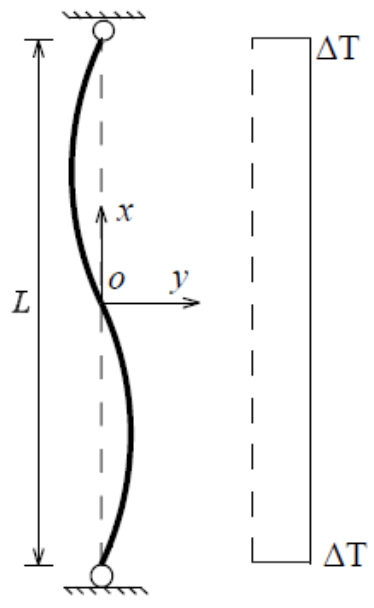

Fig. 1 Columns with anti-symmetric imperfections.

The initial curvature based on the second buckling mode of steel column can be described by

$$
y=a \sin \left(\frac{2 \pi x}{L}\right)
$$


where $\mathrm{L}$ is the span of the column.

Then the nonlinear strain-displacement relationship for any point on the cross section of steel columns can be written as

$$
\varepsilon=\varepsilon_{m}+\varepsilon_{b}=\varepsilon_{m}+y \kappa
$$

where $\varepsilon_{m}$ is the membrane strain, $\varepsilon_{b}$ is the bending strain, and $\kappa$ is the change in the curvature.

The displacements of any point on the cross section in the $\mathrm{o} x$ and oy directions are denoted as $u(\mathrm{x})$ and $v(\mathrm{x})$, respectively. If the undeformed length of the column is $\mathrm{d} s$ and deformed length of the column is $\mathrm{d} s^{*}$, then with the assumption of small strains, the membrane strain of steel columns is given by

$$
\varepsilon_{m}=\frac{1}{2} \frac{\left(d s^{*}\right)^{2}-(d s)^{2}}{(d s)^{2}}
$$

where $(d s)^{2}=(d x)^{2}+(d y)^{2},\left(d s^{*}\right)^{2}=(d x+d u)^{2}+(d y+d v)^{2}$.

The imperfect columns are assumed that $(d y / d x)^{2}<<1$ and $d u / d x<<1$, so that Eqn. (3) can be expressed as

$$
\varepsilon_{m}=u^{\prime}+g(x) v^{\prime}+\frac{1}{2}\left(v^{\prime}\right)^{2}
$$

in which ()$^{\prime}=d() / d x, g(x)=\frac{2 a \pi}{L} \cos \left(\frac{2 \pi}{L} x\right)$.

For the steel column with a small initial curvature, the bending strain can be written as

$$
\varepsilon_{b}=-y v^{\prime \prime} \text {. }
$$

In addition, the strain produced by the evaluated temperature $\Delta \mathrm{T}$ can be given as

$$
\varepsilon_{t}=\alpha \Delta T
$$

where $\varepsilon_{t}$ is the thermal strain, $\Delta T$ the temperature increment relative to its ambient value, and $\alpha$ the coefficient of thermal expansion that is set to $1.2 \times 10^{-5} /{ }^{\circ} \mathrm{C}$ in this study.

Therefore, the total strain of the column can be obtained as

$$
\varepsilon=\varepsilon_{e}+\varepsilon_{t}
$$

where $\varepsilon_{e}$ denotes the mechanical elastic strain, which consists of two components, the axial strain $\varepsilon_{e m}$ and the bending strain $\varepsilon_{e b}$. All strains are defined as positive in tension. From Eqn. (2)-(7), the mechanical axial strain and bending strain of steel column can be given as

$$
\varepsilon_{e m}=u^{\prime}+g(x) v^{\prime}+\frac{1}{2}\left(v^{\prime}\right)^{2}-\alpha \Delta T \quad \varepsilon_{e b}=-y v^{\prime \prime}
$$

The differential equations of equilibrium for a pin-ended column with imperfections under thermal loadings can be obtained with the principle of virtual work which requires

$$
\begin{gathered}
\int_{-L / 2}^{L / 2}\left[(E A)_{e q}\left(\delta u^{\prime}+g(x) \delta v^{\prime}+v^{\prime} \delta v^{\prime}\right) \varepsilon_{e m}\right. \\
\left.+(E I)_{e q} v^{\prime \prime} \delta v^{\prime \prime}\right] d x=0
\end{gathered}
$$

for all sets of kinematically admissible virtual displacements $\delta u$ and $\delta v$. In Eqn. (9), temperature-dependent cross-section properties $(E A)_{e q}$ and $\left(E I_{z}\right)_{e q}$ are defined as $(E A)_{e q}=\int_{A} E(y) d A, \quad\left(E I_{z}\right)_{e q}=\int_{A} E(y) y^{2} d A$, where $E(y)$ is the temperature-dependent Young's modulus at the coordinate $y$.

Integrating Eqn. (9) by parts leads to

$$
\begin{aligned}
& \left.(E A)_{e q} \varepsilon_{e m} \delta u\right|_{-L / 2} ^{L / 2}-\int_{-L / 2}^{L / 2}(E A)_{e q} \varepsilon_{e m}^{\prime} \delta u d x \\
& +\left.(E A)_{e q} g(x) \varepsilon_{e m} \delta v\right|_{-L / 2} ^{L / 2}-\int_{-L / 2}^{L / 2}(E A)_{e q}\left(g(x) \varepsilon_{m}\right)^{\prime} \delta v d x \\
& +\left.(E A)_{e q} v^{\prime} \varepsilon_{m} \delta v\right|_{-L / 2} ^{L / 2}-\int_{-L / 2}^{L / 2}(E A)_{e q}\left(v^{\prime} \varepsilon_{m}\right)^{\prime} \delta v d x \\
& +\left.(E I)_{e q} v^{\prime \prime} \delta v^{\prime}\right|_{-L / 2} ^{L / 2}-\left.(E I)_{e q} v^{\prime \prime \prime} \delta v\right|_{-L / 2} ^{L / 2} \\
& +\int_{-L / 2}^{L / 2}(E I)_{e q} v^{i v} \delta v d x v=0
\end{aligned}
$$

in which $v^{i v}=d^{4} v / d x^{4}$.

Then the differential equilibrium equations of imperfect columns in the axial direction can be derived from Eqn. (10) as

$$
-(E A)_{e q} \varepsilon_{e m}^{\prime}=0
$$

From Eqn. (11), it can be found that the membrane strain $\varepsilon_{e m}$ is constant. It can be written as

$$
\varepsilon_{e m}=-\frac{N}{(E A)_{e q}}
$$

where $N$ is the actual axial compression in the steel column.

In addation, the differential equilibrium equation of imperfect columns in the transversal direction can be derived from Eqn. (10) and (12) as

$$
(E I)_{e q} v^{i v}+N v^{\prime \prime}+N g^{\prime}(x)=0 .
$$

For simplicity, the following new parameter is introduced

$$
\mu^{2}=\frac{N}{(E I)_{e q}},
$$

and rearranged to yield

$$
\frac{v^{i x}}{\mu^{2}}+v^{\prime \prime}=-g^{\prime}(x)
$$

The boundary conditions for the pin-ended column are given by

$$
\left.v\right|_{x= \pm L / 2}=0 \text { and }\left.\quad v^{\prime \prime}\right|_{x= \pm L / 2}=0
$$

Combining Eqn. (15) with Eqn. (16) solves the transversal displacement as

$$
v=a \eta^{2} \frac{\sin \left(\frac{2 \pi x}{L}\right)}{\pi^{2}-\eta^{2}}
$$

where $\eta=\mu L / 2$ is the axial force coefficient.

The mechanical axial strain given by Eqn. (12) is constant. It should be equal to the axial strain averaged mathematically over the column length L calculated form Eqn. (8), which leads to the nonlinear relationship between the thermal loading and the axial compression $\mathrm{N}$ as

$$
\begin{aligned}
\varepsilon_{e m} & =-\frac{N}{(E A)_{e q}} \\
& =\frac{1}{L} \int_{-L / 2}^{L / 2}\left(u^{\prime}+g(x) v^{\prime}+\frac{1}{2}\left(v^{\prime}\right)^{2}-\alpha \Delta T\right) d x
\end{aligned}
$$

Because the axial displacement at both ends of steel columns are fully prevented as such

$$
\frac{1}{L} \int_{-L / 2}^{L / 2} u^{\prime} d x=0
$$

and rewriting the left-hand side of Eqn. (18) as 


$$
\varepsilon_{e m}=-\frac{N}{(E A)_{e q}}=-\frac{N}{(E I)_{e q}} \frac{(E I)_{e q}}{(E A)_{e q}}=-\mu^{2} i^{2}
$$

where $i$ is the modified radius of gyration of the cross section about the $\mathrm{z}$ axis given by $i=\sqrt{(E I)_{e q} /(E A)_{e q}}$.

Then the nonlinear equilibrium condition for pin-end columns with second-mode imperfections can be obtained by substituting Eqn. (17) into Eqn. (18) as

$$
\left(\frac{a}{L}\right)^{2} \frac{4 \eta^{2} \pi^{2}\left[2 \pi^{3}+\eta^{2}(1-2 \pi)\right]}{\left(\pi^{2}-\eta^{2}\right)^{2}}-\varepsilon_{t}+\frac{4 \eta^{2}}{\lambda^{2}}=0
$$

where $\lambda=L / i$ is defined as the modified slenderness ratio of the imperfect column.

For a specific column (with a known slenderness ratio), if the thermal loading is given, the axial force coefficient can be obtained by solving Eqn. (21) numerically. Then the transversal displacement $\mathrm{v}$ can be calculated with Eqn. (17). Also, the axial stress and bending stress can be computed by Eqn. (4) and (5).

\section{Results}

The equilibrium condition of perfect columns can be obtained by substituting a $=0$ into Eqn. (21) as

$$
\frac{4 \eta^{2}}{\lambda^{2}}-\varepsilon_{t}=0
$$

Eqn. (22) provides the same equilibrium obtained by Cai and Feng [9] for perfect pin-ended columns.

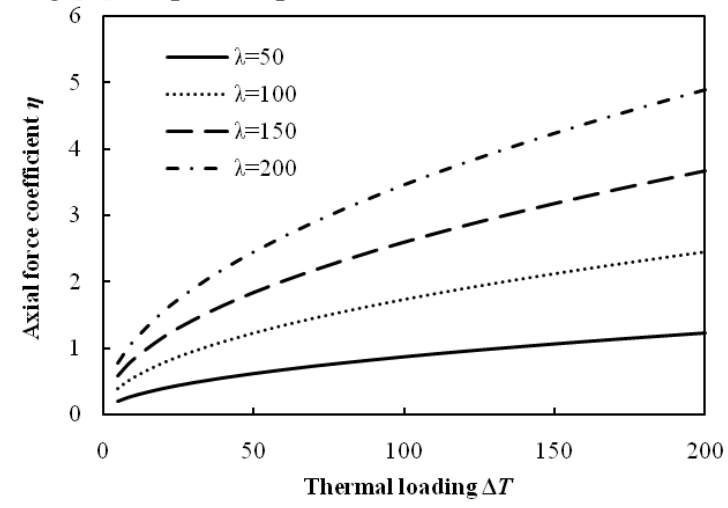

Fig. 2 Axial force coefficient $\eta$ against thermal loading $\Delta T$ for perfect columns.

Figure 2 shows the relation between the axial force coefficient $\eta$ and thermal loading $\Delta \mathrm{T}$ for perfect columns with different modified slenderness ratios. It is clear from the figure that the axial compression increases with the thermal loading, but the rising trend becomes slow at higher temperatures. Furthermore, the effect of the thermal loading is more notable if the modified slenderness ratio is set higher.

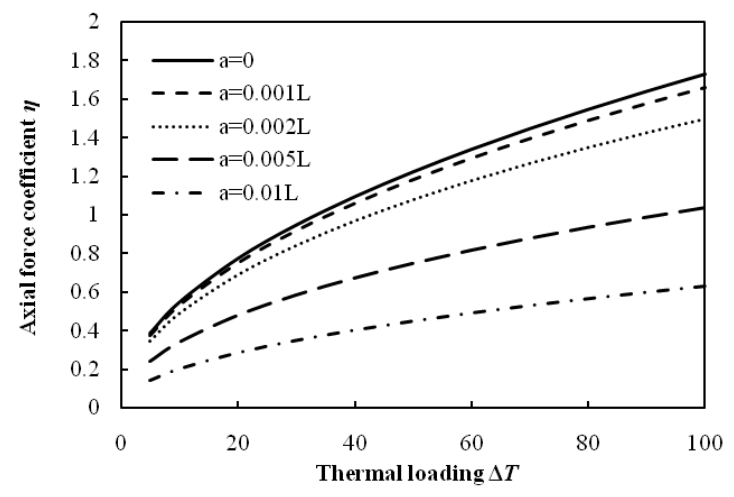

(a) Axial force coefficient $\eta$

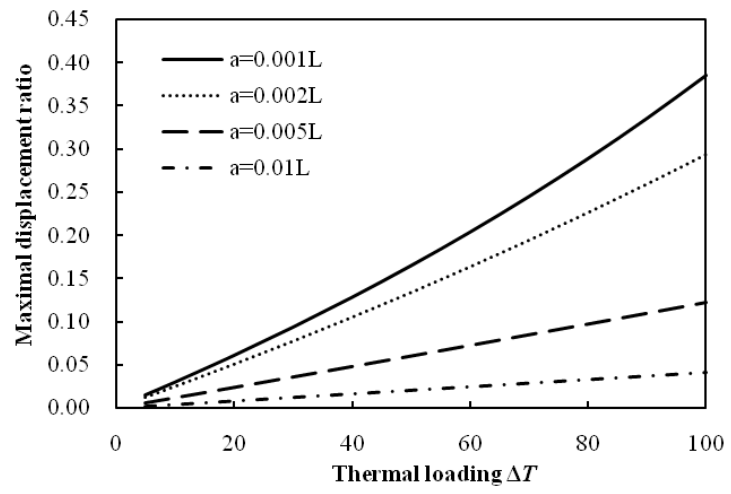

(b) Maximal deflection

Fig. 3 The influence of the anti-symmetric imperfection on the thermal behavior with $\lambda=100$.

The influence of the anti-symmetric imperfection on the thermal behavior is shown in Fig. 3. The modified slenderness ratio is assumed to be 100, and the size of the imperfection $a$ corresponds to $0.001 \mathrm{~L}, 0.002 \mathrm{~L}, 0.005 \mathrm{~L}$ and $0.01 \mathrm{~L}$ in Fig. 3, respectively. The results for the perfect column $(a=0)$ are also presented in Fig. 3 (a) for comparison. It can be seen that the imperfections do reduce the axial column compression, and the axial force coefficient decrease with an increasing scale of the second-mode initial imperfection. This is because the axial compression of columns has been changed to compression and bending behavior by the imperfection.

Furthermore, the effect of the initial imperfection is more notable when the temperature is higher.

From Eqn. (17), the maximal transversal displacement occurs at $x=L / 4$, which is given as

$$
v_{\max }=\frac{a \eta^{2}}{\pi^{2}-\eta^{2}}
$$

The relation between the maximal displacement ratio $v_{\max } / a$ and the thermal loading is shown in Fig. 3 (b). It can be found from this figure that the maximal transversal displacement ratio increases with the thermal loading. However, the ratio decreases with the increasing imperfection scale. It should be noted the maximal transversal displacement ratio is a relative value, the maximal transversal displacement increases with the increase of the initial imperfection. 


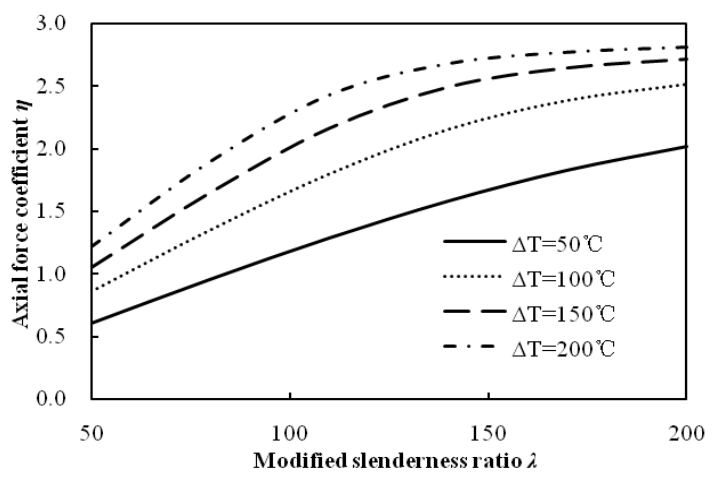

(a) Axial force coefficient $\eta$

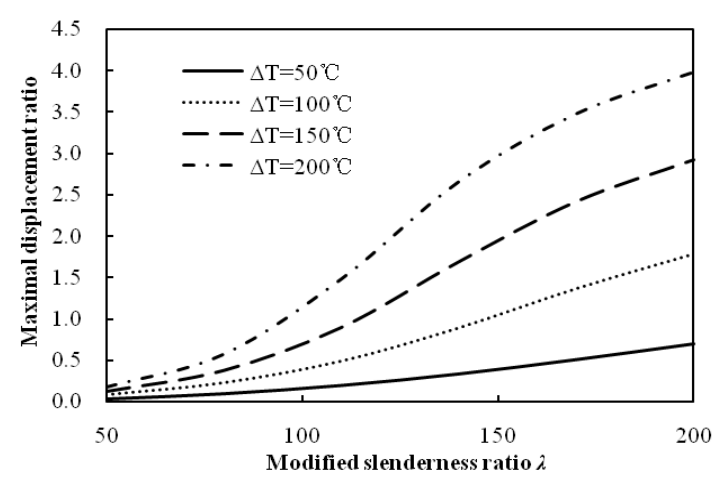

(b) Maximal deflection

Fig. 4 Thermal behavior against modified slenderness ratios.

Figure 4 shows the influence of the modified slenderness ratio on the thermal behavior of imperfect columns with the size of the imperfection $a=0.002 L$. It can be seen that the axial compression and transversal displacement increase with the modified slenderness ratio of the column under the same thermal loading. However, the increase of the axial force coefficient becomes very slow when the modified slenderness ratio of the column is larger. Moreover, the increase of the maximal transversal displacement is more obvious for the column under larger thermal loading.

\section{Conclusions}

Initial imperfections of columns are often assumed to have the symmetric shape (the first buckling mode). In this paper, columns with anti-symmetric imperfection shape are considered. The thermal behavior of imperfect columns has been investigated. The principal of virtual work was used to establish the differential equations of equilibrium of the imperfect column in the axial and transversal directions. After that the relationship between the evaluated temperature and the axial compression was obtained. The results show that the axial compression and transversal displacement increase with the thermal loading. The anti-symmetric imperfection contributes to the reduction of the axial compression. It has been found that increasing the imperfection scale leads to the reduction of the axial force coefficient and maximal displacement ratio $v_{\max } / a$. Furthermore, the effect of the initial imperfection is more significant when the temperature is raised. It can also be found that the axial compression and transversal displacement increase with the modified slenderness ratio of the imperfect column.

\section{Acknowledgments}

The work presented in this article was supported by the National Natural Science Foundation of China (Grant No. 51308106 and No. 51278116), the Natural Science Foundation of Jiangsu Province (Grant No. BK20130614), the Specialized Research Fund for the Doctoral Program of Higher Education (Grant No. 20130092120018) a Project Funded by the Priority Academic Program Development of Jiangsu Higher Education Institutions and the Excellent Young Teachers Program of Southeast University. Authors also thank the anonymous reviewers for their valuable comments and thoughtful suggestions which improved the quality of the presented work.

\section{References}

[1] Simitses G.J., An Introduction to the Elastic Stability of Structures, Prentice-Hall, New Jersey, 1976.

[2] Timoshenko S., Gere J.M., Theory of elastic stability, McGraw-Hill, New York, 1961.

[3] Buchanan, A.H., Structural design for fire safety, John Wiley and Sons Ltd, 2001.

[4] Wang Y.C., Steel and composite structures-behavior and design for fire safety, Spon Press, 2002.

[5] Culver C., Steel column buckling under thermal gradients, J. Struct. Eng., 92(1972)1853-1865.

[6] Poh K.W., Bennetts I.D., Analysis of structural members under elevated temperature conditions, J. Struct. Eng., 121(1995)664-675.

[7]Toh W.S., Tan K.H., and Fung T.C., Compressive resistance of steel columns in fire: The Rankine approach, J. Struct. Eng., 126(2000)398-405.

[8]Yang, K.C., Lee, H.H., Chan, O. Performance of steel H columns loaded under uniform temperature, J Construct Steel Res, 62(2006)262-270.

[9]Cai, J.G., Feng, J., Thermal buckling of rotationally restrained steel columns, J Construct Steel Res, 66(2010) 835-841.

[10]Cai, J.G., Feng, J., Zhang, J. Thermoelastic buckling of steel columns with load-dependent supports, Int J Nonlinear Mech, 47(2012) 8-15

[11]Correia, A.J.P.M., Rodrigues, J.P.C. , Gomes, F.C.T., A simplified calculation method for fire design of steel columns with restrained thermal elongation,Comput. Struct., 116 (2013) 20-34

[12]Alam, M.S., Billah, A.H.M.M., Quayyum, S., Ashraf, M., Rafi, A.N.M., Rteil, A. Fire performance curves for unprotected HSS steel columns. Steel Compos Struct, 15 (2013) 705-724

[13]Birman, V. Life-span of imperfect composite columns subjected to creep, Mech Res Commun, 21(1994) 493-499

[14]Coelho, A.M.G., Simao, P.D., Wadee, M.A., Imperfection sensitivity of column instability revisited. J Construct Steel Res, 90(2013)265-282.

[15] Xu, S.P., Xu, M.R., Wang, C.M. Stability Analysis of Nonlocal Elastic Columns with Initial Imperfection. Math Probl Eng, (2013) 341232

[16]Plaut, R. H., Dillard, D.A., Virgin, L.N. Postbuckling of elastic columns with second-mode imperfection. J Eng Mech ASCE, 132 (2006), 898901.

[17]Cai, J.G., Xu, Y.X., Feng, J., Zhang, J. Buckling and post-buckling of rotationally restrained columns with imperfections, Sci China Phy Mech Astron 55(2012): 1519-1522 